BMJ Paediatrics Open

\title{
Congenital haemangiomas: a single-centre retrospective review
}

\author{
Victoire Braun, ${ }^{1}$ Sorilla Prey (D , , ${ }^{1,2}$ Carlotta Gurioli, ${ }^{3}$ Franck Boralevi, ${ }^{1,2}$ \\ Alain Taieb, ${ }^{1,2}$ Nicolas Grenier, ${ }^{4}$ Maya Loot, ${ }^{5}$ Marie-Laure Jullie, ${ }^{6}$ \\ Christine Léauté-Labrèze ${ }^{1,2}$
}

To cite: Braun V, Prey S, Gurioli C, et al. Congenital haemangiomas: a single-centre retrospective review. BMJ Paediatrics Open 2020;4:e000816. doi:10.1136/ bmjpo-2020-000816

VB and SP contributed equally.

VB and SP are joint first authors.

Received 23 July 2020 Revised 29 September 2020 Accepted 20 0ctober 2020

Check for updates

(C) Author(s) (or their employer(s)) 2020. Re-use permitted under CC BY-NC. No commercial re-use. See rights and permissions. Published by BMJ.

${ }^{1}$ Dermatology, CHU de Bordeaux, Bordeaux, France 2INSERM U1035, Université de Bordeaux, Talence, France ${ }^{3}$ Department of Specialized, Experimental and Diagnostic Medicine, Dermatology, University of Bologna, University of Bologna, Bologna, EmiliaRomagna, Italy

${ }^{4}$ Department of Radiology, CHU de Bordeaux, Bordeaux, Aquitaine, France

${ }^{5}$ Paediatric Surgery Department, $\mathrm{CHU}$ de Bordeaux, Bordeaux, Aquitaine, France

${ }^{6}$ Pathology Department, CHU de Bordeaux, PESSAC, Aquitaine, France

Correspondence to Dr Sorilla Prey; sorilla.prey@ chu-bordeaux.fr

\section{ABSTRACT}

Objective Congenital haemangiomas $(\mathrm{CHs})$ are rare, benign vascular tumours that are fully developed at birth. Three subtypes of $\mathrm{CHs}$ have been described based on clinical behaviour: rapidly involuting $\mathrm{CHs}$ ( $\mathrm{RICHs}$ ), non-involuting $\mathrm{CHs}$ ( $\mathrm{NICHs}$ ) and partially involuting $\mathrm{CHs}$ (PICHs). We explore in our study clinical, evolutionary and paraclinical characteristics of the three $\mathrm{CH}$ subtypes.

Design Children with $\mathrm{CH}$ attending our department of paediatric dermatology at Bordeaux University Hospital over a 13-year period were retrospectively included. Epidemiological, clinical and evolutionary data, photographs and imaging results were reviewed. All available tissue samples were histologically examined. Results We included 57 patients: 22 with RICH, 22 with $\mathrm{NICH}$ and 13 with PICH. Males predominated (ratio 1.7); the most common $\mathrm{CH}$ location was on the limbs. $\mathrm{RICH}, \mathrm{NICH}$ and PICH exhibited overlapping characteristics; all were single telangiectatic lesions with pale peripheral halos. At birth, NICHs were flat but RICHs and PICHs bulky. The median age at complete $\mathrm{RICH}$ involution was 12 months. One-third of $\mathrm{CHs}$ that appeared RICH-like at birth underwent incomplete involution to become PICHs. Heart failure and thrombocytopenia were rare complications. PICHs were frequently ulcerated. Pain was common for $\mathrm{NICH}$ and $\mathrm{PICH}$. The imaging and histological data of the three $\mathrm{CH}$ subtypes were rather similar.

Conclusions We describe the characteristics and evolution of the three $\mathrm{CH}$ subtypes using a case series. Certain overlapping features were apparent, reinforcing the hypothesis that RICH, NICH and PICH lie on the same pathological spectrum.

\section{INTRODUCTION}

Congenital haemangiomas (CHs) are rare, benign vascular tumours that proliferate in utero and are fully developed at birth ${ }^{1}$; CHs are, thus, unlike infantile haemangiomas (IHs) that appear only within the first weeks after birth. ${ }^{2}$ Two types of $\mathrm{CH}$ were first described by reference to their natural history and clinical characteristics: rapidly involuting $\mathrm{CH}(\mathrm{RICH})^{3}$ that regresses spontaneously within the first year of life, and noninvoluting $\mathrm{CH}(\mathrm{NICH})^{4}$ that remains stable and grows as the child grows. A third type has

\section{What is known about the subject?}

Congenital haemangiomas are vascular tumours of infancy that are fully developed at birth.

- Three subtypes of congenital haemangiomas have been described based on clinical behaviour: rapidly involuting congenital haemangioma, non-involuting congenital haemangioma or partially involuting congenital haemangioma tumours.

- The pathophysiology of congenital haemangiomas remains unclear, and factors determining evolution after birth remain unknown.

\section{What this study adds?}

Long-term follow-up reveals that one-third of congenital haemangiomas that are rapidly involuting congenital haemangioma (RICH)-like at birth undergo only partial involution (and are thus partially involuting congenital haemangioma (PICHs)). Ulceration is particularly common in PICH patients.

- Patient with non-involuting congenital haemangioma (NICH) may develop late neuropathic pain on their lesion, which can be caused by intralesional nerve dystrophy.

RICH, NICH and PICH exhibit many overlapping characteristics, suggesting that they lie on the same disease spectrum.

recently been described: partially involuting $\mathrm{CH}(\mathrm{PICH})^{5}$ that regresses incompletely to then stabilise.

$\mathrm{CH}$ usually presents as a unique well-limited lesion that is red-purple in colour, covered with a fine or coarse telangiectasia, and frequently surrounded by a pale peripheral halo. RICH often looks like a raised tumour; NICH forms a flat plaque or macule. A PICH initially looks similar to an RICH, but undergoes only partial involution; the final residual lesion mimics NICH. The pathophysiology of $\mathrm{CH}$ remains unclear, and factors determining $\mathrm{CH}$ evolution after birth are unknown. We explored the natural history of CHs, their clinical, pathological and evolutionary characteristics, over 13 years. 


\section{PATIENTS AND METHODS}

Information on CH patients logged from 2004 to 2016 was retrieved from the database of the department of paediatric dermatology at Bordeaux University Hospital. Non-opposition to the use of patient medical data was collected from legal representatives. Epidemiological and clinical features, complications (in particular pain), treatments and evolutionary data were collected, as were all available photographs; all data were reviewed by VB and CL-L. If biopsy or excisional tissue samples were available, immunohistochemistry staining for glucose transporter 1 (GLUT-1) were done for the diagnosis (usually negative in $\mathrm{CH}$ ); and $\mathrm{S} 100$ protein (PS100) to assess intralesional nerve morphology as some patients complained from pain. We excluded cases whose clinical characteristics were inconsistent with a $\mathrm{CH}$ diagnosis, and those for whom the follow-up duration was too short to allow identification of the $\mathrm{CH}$ subgroup (RICH, NICH or PICH).

\section{PATIENT AND PUBLIC INVOLVEMENT STATEMENT}

Patients were not directly involved in the design of this study.

\section{RESULTS}

\section{Patients}

We initially identified 69 patients of interest, of whom 12 were excluded because of uncertain diagnoses $(n=5)$ or follow-up durations inadequate to support the diagnoses $(\mathrm{n}=7)$; we finally included 57 patients: 22 with RICH, 22 with NICH and 13 with PICH (table 1). All patients had a single lesion. CHs' characteristics were detailed in table 2.

\section{Antenatal and birth}

In five patients, $\mathrm{CH}$ had been detected via antenatal ultrasonography and/or magnetic resonance imaging (three RICH and two PICH cases). Four of these CHs were located in the head-and-neck region, and one on an upper limb. All tumour diameters were $>2 \mathrm{~cm}(2-5 \mathrm{~cm}$, $\mathrm{n}=3 ;>5 \mathrm{~cm}, \mathrm{n}=2)$. Most diagnoses were made during the second $(n=3)$ or third $(n=1)$ trimester (the timing was unclear in one case). Certain obstetrical complications were reported: one risk of premature delivery, one group-B streptococcal maternal colonisation, one case of gestational diabetes, and one case of peripartum haemorrhage. Two patients (one RICH and one PICH case) developed fetal heart failure and one required delivery via caesarean section. $\mathrm{CH}$-associated comorbidities included two cases of macrocrania (one case had a family history of macrocephaly, and the other exhibited both developmental delay and polydactyly), one septal ventricular defect and one atrial septal defect that lacked clinical significance and one case of hypogammaglobulinemia with recurrent infections. The maternal medical histories included one therapeutic abortion because of left ventricular hypoplasia, and single cases of Sjögren's syndrome associated with systemic lupus erythematosus, Basedow's disease, epilepsy, Willebrand's disease and renal cancer. The median patient age at first consultation was 2.7 weeks for RICH, 4.1 weeks for PICH, but 58 months for NICH patients.

\section{Evolution}

The clinical and evolutionary characteristics of the 57 CHs allowed us to identify 22 RICHs (figure 1), 22 NICHs (figure 2) and 13 PICHs (figure 3).

RICH involution began at a median age of 4.0 weeks. Complete involution was confirmed within less than 1 year in 13 patients and after more than 1 year in 8

Table 1 Epidemiological characteristics of the 57 patients with $\mathrm{CH}$

\begin{tabular}{|c|c|c|c|c|}
\hline & All $\mathrm{CH} \mathrm{n}=57$ & RICH n=22 & NICH $n=22$ & $\mathrm{PICH} n=13$ \\
\hline Female, n (\%) & $21(37)$ & 6 & 8 & 7 \\
\hline Median age at first consultation (weeks) (min-max) & $6(0.1-836)$ & $2.7(0.1-11.7)$ & $40.2(1.3-836)$ & $4.1(0.4-116)$ \\
\hline Median duration of follow-up (months) (min-max) & $37(0-199)$ & $35(4-159)$ & $-25(0-199)$ & $52(9-137)$ \\
\hline Prematurity, $\mathrm{n}$ & 3 & 0 & 2 & 1 \\
\hline Birth weight average (grams) & 3286 & & & \\
\hline$<2500 \mathrm{~g}, \mathrm{n}$ & 2 & 0 & 0 & 2 \\
\hline$>4000 \mathrm{~g}, \mathrm{n}$ & 3 & 1 & 1 & 1 \\
\hline
\end{tabular}

$\mathrm{CH}$, congenital haemangioma; $\mathrm{NICH}$, non-involuting congenital haemangioma; $\mathrm{PICH}$, partially involuting congenital haemangioma; $\mathrm{RICH}$, rapidly involuting congenital haemangioma. 
Table 2 Clinical and semiological characteristics of the $57 \mathrm{CHs}$

\begin{tabular}{|c|c|c|c|c|}
\hline & All $\mathrm{CH}$ & RICH & RICH & $\mathrm{PICH}$ \\
\hline & $\mathrm{n}=57$ & $\mathrm{n}=22$ & $\mathrm{n}=22$ & $n=13$ \\
\hline \multicolumn{5}{|l|}{ Location, n (\%) } \\
\hline head and neck & $19(33)$ & 6 & 7 & 5 \\
\hline Trunk & $9(16)$ & 3 & 5 & 1 \\
\hline Limbs & $29(51)$ & 12 & 10 & 7 \\
\hline Upper limbs & $12(21)$ & 5 & 5 & 2 \\
\hline lower limbs & $17(30)$ & 7 & 5 & 5 \\
\hline \multicolumn{5}{|l|}{ Size, n (\%) } \\
\hline$<2 \mathrm{~cm}$ & $11(19)$ & 4 & 6 & 1 \\
\hline $2-5 \mathrm{~cm}$ & $27(47)$ & 13 & 7 & 7 \\
\hline$>5 \mathrm{~cm}$ & $19(33)$ & 5 & 9 & 5 \\
\hline \multicolumn{5}{|l|}{ Shape, n (\%) } \\
\hline Macula & $14(24)$ & 0 & 14 & 0 \\
\hline Infiltrated plaque & $18(33)$ & 8 & 8 & 2 \\
\hline Bulky raised tumor & $25(44)$ & 14 & 0 & 11 \\
\hline Telangiectasia, n (\%) & $55(97)$ & $22(100 \%)$ & $20(91 \%)$ & $13(100 \%)$ \\
\hline Peripheral pale halo, n (\%) & $33(58)$ & 9 & 16 & 8 \\
\hline Peripheral draining veins (\%) & $9(16)$ & 2 & 6 & 1 \\
\hline Murmur, $\mathrm{n}$ & 0 & 0 & 0 & 0 \\
\hline Pulsatility, $n$ & 1 & 0 & 1 & 0 \\
\hline Warm on palpation, $\mathrm{n}$ & 6 & 1 & 3 & 2 \\
\hline Other vascular anomalies, $\mathrm{n}$ & $6^{\star}$ & 2 & 3 & 1 \\
\hline
\end{tabular}

*It was exclusively infantile haemangiomas or port-wine stains.

$\mathrm{CHs}$, congenital haemangiomas; $\mathrm{PICH}$, partially involuting congenital haemangioma; $\mathrm{RICH}$, rapidly involuting congenital haemangioma.

(median confirmation time, 12 months (min-max 4-31 months)). One patient with bulky raised lesion, underwent $\mathrm{CH}$ excision surgery on day 3 of life.

The 13 PICH cases were all initially diagnosed with RICH; the presentations were similar. In 12 patients,

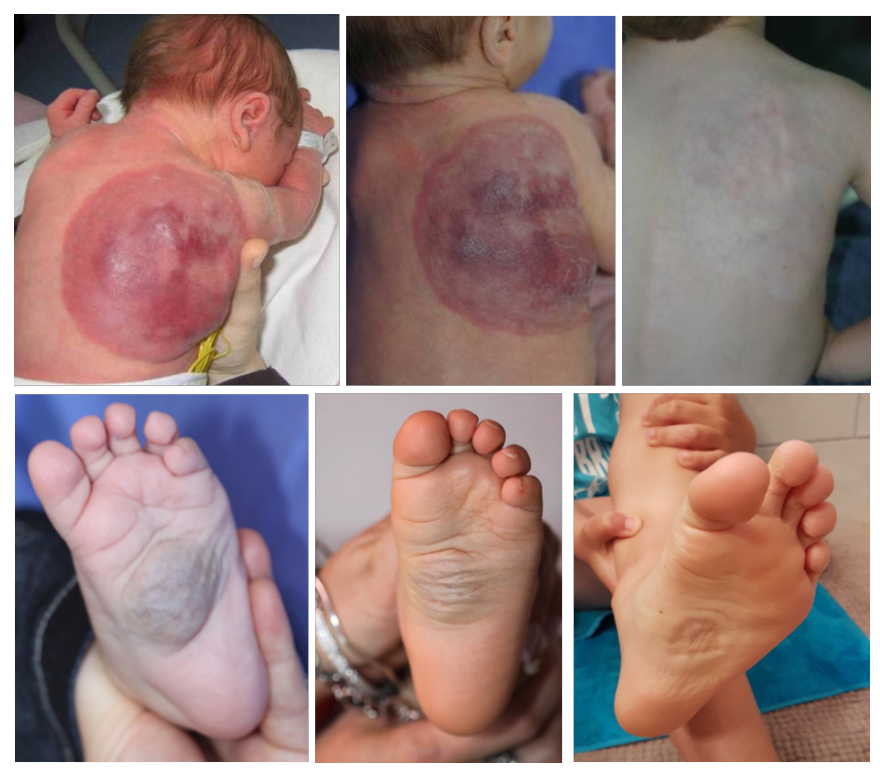

Figure 1 Rapidly involuting congenital haemangiomas. initial regression commenced at a median age of 7 weeks but the lesions stabilised at a median age of 12.6 months. One patient had been prenatally diagnosed with $\mathrm{CH}$; ultrasound follow-up revealed partial involution in utero. All PICH patients exhibited residual telangiectatic sequelae.

In the 22 patients with NICHs, the $\mathrm{CHs}$ remained stable and grew as the children grew.

The following sequelae were observed after RICH regression: anetoderma $(n=6)$, subcutaneous atrophy

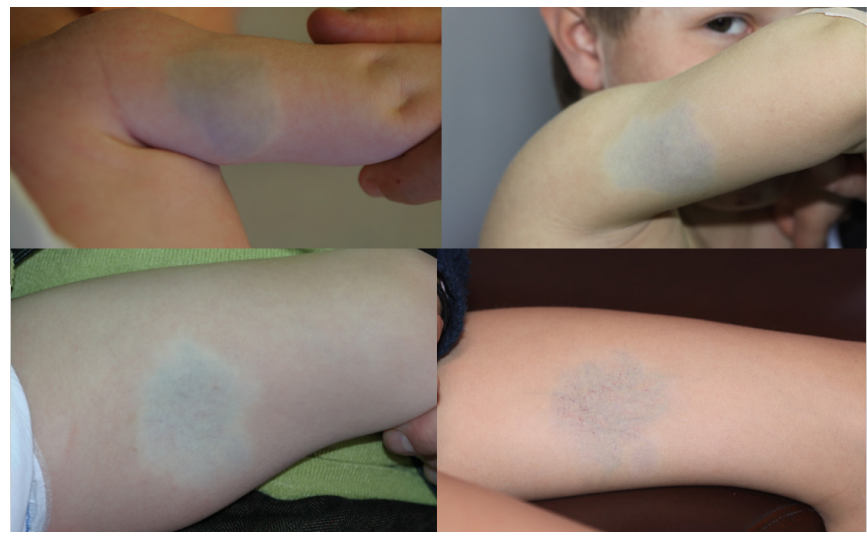

Figure 2 Non-involuting congenital haemangiomas. 


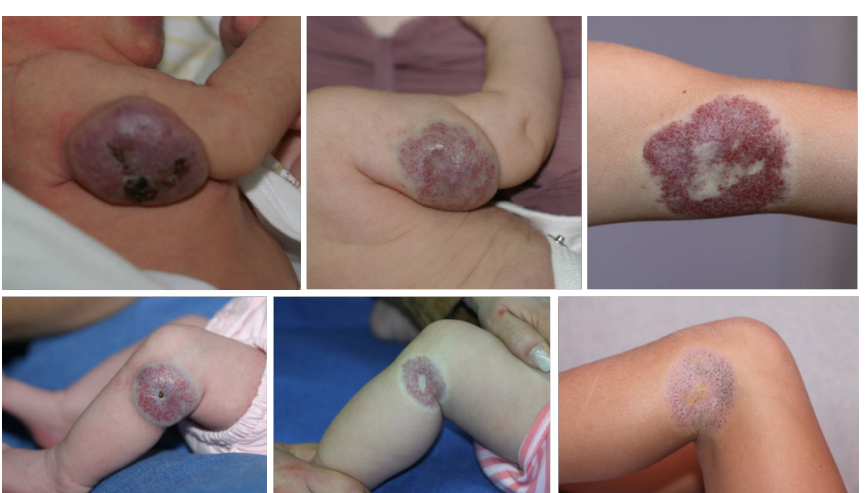

Figure 3 Partially involuting congenital haemangiomas.

$(\mathrm{n}=11)$, residual telangiectasia $(\mathrm{n}=4)$ and pale or bluish areas $(\mathrm{n}=8)$. Residual, dysplastic draining veins were evident in $10 \mathrm{NICH}, 5 \mathrm{PICH}$ and 2 RICH cases.

\section{Complications}

Table 3 lists the $\mathrm{CH}$ complications.

Two children developed heart failure in utero. The first had a large cervical PICH, regression of which commenced in utero; delivery was induced at 33 weeks gestational age because of fetal rhythmic abnormalities. The cardiac function normalised within a few hours after birth. The other child had a large RICH on his elbow. He presented (in utero) with moderate cardiac decompensation, right heart dilatation, and a small pericardial effusion; he required intensive care immediately after birth. Excisional surgery was performed at 3 days of life, with a favourable outcome.

Transient thrombocytopenia was observed in two patients in the first few days of life (platelet counts of 102 and $118 \mathrm{~g} / \mathrm{L})$; spontaneous normalisation was noted on day 2 (one child) and day 9 (one child) of life without any haemorrhagic complication.

Ulceration developed in six $\mathrm{CH}$ cases, five of which were PICHs (39\%). A massive acute haemorrhage developed (at an age of 4 weeks) in one patient with a large ulcerated PICH of the thigh. He developed anaemia (haemoglobin level $60 \mathrm{~g} / \mathrm{L}$ ) and required several transfusions. After corticosteroid therapy failed, surgical excision performed at the age of 8 weeks was successful.

Other reported complications were swelling with heat or fever (single rich, NICH and PICH patients), transient alopecia (one patient with a scalp rich), infection (one PICH patient) and functional discomfort when crawling (a child with a leg PICH).

During long-term follow-up, pain was reported by $16 \mathrm{CHs,}$ mainly NICH (41\%) and PICH (39\%). Symptoms were often subjective; abnormal sensations evoked neuropathic pain.

\section{Treatment}

Twelve patients (21\%) underwent surgical excision: one RICH patient at 3 days of life because of heart failure, six PICH patients at a mean age of 29.5 months and five NICH patients at a mean age of 81 months. The CHs were located on the head-and-neck regions of five patients, the trunks of three, and the limbs of four; two children required expansion prostheses prior surgery. The principal surgical indications were aesthetic concerns, pain or bleeding. Single patients with NICH and PICH received oral and topical beta-blockers, but these were ineffective. One patient with a facial NICH underwent two percutaneous scleroses: the lesional size increased after treatment.

\section{Imaging}

Thirty-three patients underwent at least one Doppler ultrasound imaging session; data were available for 29 (11 RICH, $9 \mathrm{NICH}$ and $9 \mathrm{PICH})$. Imaging was performed before the age of 3 months for all patients with RICH, only one with $\mathrm{NICH}$ and seven with PICH. All images (except one defective image) revealed highly vascularised tumours that were usually well limited, with many enlarged veins and arteries and high-velocity blood flows. All tumours were hypoechoic (except for single hyperechoic RICH and PICH tumours) but were either homogeneous or heterogeneous. Calcifications were evident in two RICHs and one PICH. An arteriovenous shunt was present in one PICH. MRI was performed on two patients (one with an NICH and one with a PICH),

Table 3 Complications of the $57 \mathrm{CHs}$

\begin{tabular}{|c|c|c|c|c|}
\hline & All $\mathrm{CH} n=57$ & $\mathrm{RICH}$ n=22 & NICH n=22 & $\mathrm{PICH} n=13$ \\
\hline \multicolumn{5}{|l|}{ Early complications } \\
\hline Ulceration, n (\%) & $6(11)$ & 1 & 0 & 5 \\
\hline Haemorrhage, $n(\%)$ & $1(2)$ & 0 & 0 & 1 \\
\hline Thrombocytopenia, n (\%) & $2(4)$ & 1 & 0 & 1 \\
\hline Heart failure, $\mathrm{n}(\%)$ & $2(4)$ & 1 & 0 & 1 \\
\hline \multicolumn{5}{|c|}{ Late complications during follow-up } \\
\hline Pain, n (\%) & $16(28)$ & 2 & 9 & 5 \\
\hline Superficial thrombosis, n (\%) & $3(5)$ & 1 & 1 & 1 \\
\hline Necrosis, n (\%) & $2(4)$ & 1 & 1 & 0 \\
\hline Other complication, n (\%) & $5(9)$ & 2 & 1 & 2 \\
\hline
\end{tabular}

$\mathrm{CH}$, congenital haemangiomas; $\mathrm{NICH}$, non-involuting congenital haemangioma; $\mathrm{PICH}$, partially involuting congenital haemangioma; $\mathrm{RICH}$, rapidly involuting congenital haemangioma. 
revealing well-circumscribed tumours hyperintense on T2-weighted sequences and homogeneous after T1-gadolinium enhancement.

\section{Histology}

Histopathological examinations of lesional tissues (biopsy or excisional specimens) were performed for 13 patients (3 RICH, 5 NICH and 6 PICH patients). One NICH specimen could not be analysed because the histological material was lost. The CHs exhibited variably sized capillary lobules with draining arteries and normal or dysplastic veins, surrounded by fibrous tissue. A maturation gradient was evident; some lobules featured small compact capillaries, but some larger lobules seemed more mature, exhibiting dilated, larger draining channels and prominent fibrosis. Tumour architecture could not be analysed in the biopsy samples of two RICH patients because the samples were too small. GLUT-1 staining was negative for all 13 cases. PS100 immunostaining revealed variably sized, intralesional nerve bundles in all cases, with four instances of nerve hypertrophy (in two PICH and two NICH cases).

\section{DISCUSSION}

Our series of 57 cases followed for 3-13 years (median 5.6 years) confirms that $\mathrm{CH}$ is rare $(5 \mathrm{CHs}$ were referred annually to our department, compared with 200 complicated IHs). A male predominance was evident (sex ratio 1.7), although the (very limited) existing literature indicates that the sex ratio is equally balanced unlike the IH situation (IH is more common in females). ${ }^{6}$ Unlike IHs, CHs were not more common in premature infants; the caesarean section frequency was similar to that of the overall French population. ${ }^{7}$

The first consultation was scheduled much earlier for infants with RICH than those with NICH; as RICH and PICH are alarmingly bulky at birth. As reported in the literature, ${ }^{89}$ most CHs were on the limbs, followed by the headand-neck region and the trunk. Most $\mathrm{CHs}$ were $>2 \mathrm{~cm}$ in diameter; one-third (especially NICHs) were $>5 \mathrm{~cm}$ in diameter, explained by the older age at first consultation of NICH patients; NICHs grow with the child.

$\mathrm{CH}$ is often obvious; no elaborate diagnostic investigation is required. However, if the presentation is atypical, a skin biopsy and radiological examination must be considered to eliminate other vascular tumours such as a kaposiform haemangioendothelioma or a tufted angioma that may exhibit similar clinical features ${ }^{810}$ but are associated with bothersome prognoses. NICHs are essentially flat; RICHs and PICHs exhibit exophytic presentations. However, the three $\mathrm{CH}$ subtypes exhibited similar clinical characteristics: all were solitary, most featured telangiectasias, and more than half exhibited peripheral vasoconstrictive halos. Also, all three $\mathrm{CH}$ subtypes shared imaging features. Colour Doppler ultrasonography is non-invasive and is the imaging technique of choice in children. CHs are usually located in subcutaneous fat, and are both heterogeneous and hypoechoic, exhibiting multiple arteries and veins, high-velocity blood flow ${ }^{5}$ and, sometimes, calcifications ${ }^{11}$ (noted by us in three cases). Vascular microshunts are more frequent in NICHs than other $\mathrm{CHs}^{11}$; we found such a shunt in one PICH patient. The resistance index is a reliable maturation parameter, increasing as the tumour involutes. ${ }^{12}$ On MRI, CHs were well limited, exhibited homogeneous or patchy enhancement, were hyperintense on T2-weighted sequences, and evidenced flow voids and fat stranding. ${ }^{511} 13 \mathrm{CHs}$ are increasingly diagnosed prenatally ${ }^{14}$ (especially RICHs, which are large).$^{15}$

RICH, NICH and PICH share histological features: variably sized capillary lobules with draining arteries and associated dysplastic veins and lymphatic vessels, surrounded by fibrous tissue, as confirmed by a recent histological series of 55 cases. ${ }^{16}$ In contrast to classical IHs, GLUT-1 staining is always negative. We observed numerous intra-lesional nerve bundles in capillary lobules and/or fibrous tissues; we hypothesise that it may explain the pain frequently reported during follow-up (especially by NICH and PICH patients). Neural components have previously been reported in congenital vascular malformations, such as arteriovenous and pure venous malformations, ${ }^{17}$ but not CHs. Somatic mosaic mutations in GNAQ and GNA11 were recently identified in both RICH and NICH, ${ }^{18}$ which is a supplemental argument for considering that they belong to the same spectrum.

$\mathrm{CHs}$ had associated with few complications. Yet, large CHs may cause haemodynamic complications because of their high blood-flow rates. Usually, cardiopathy is transient, resolving after involution. However, Weitz et al (in a literature review) reported a mortality rate of $30 \%{ }^{19}$; large CHs should be closely monitored. Two of our cases exhibited transient mild thrombocytopenia at birth. Retrospective case series of Baselga et $a l^{20}$ reported 7 RICHs of diameter $>5 \mathrm{~cm}$, all accompanied by moderate thrombocytopenia; the nadir came in the first week of life, with rapid improvements by 2 weeks. $\mathrm{CH}$ seems to differ from Kasabach-Meritt syndrome, in which the haematological anomalies are more severe, persisting for weeks to months as tumour size increases. Almost half of our PICH cases exhibited central ulcerations, which may thus predict partial CH involution. Such cases require special care; several life-threatening massive haemorrhages have been reported, ${ }^{12} 2122$ as in one of our patients. High-flow bleeding may reflect wall erosion of a large vessel located just under the ulcer. If a patient presents with RICH at birth, it is difficult to assess if the lesion will totally regress or evolve to become a PICH. We found that $37 \%$ of $\mathrm{CHs}$ that appeared to be RICHs at birth regressed, only partially, to become PICHs. In some cases, the residual tumours were indistinguishable from NICHs, as previously reported. ${ }^{5}{ }^{23}$ RICH and PICH regression begins at median ages of 4 and 7 weeks respectively; this does not allow of initial differentiation. However, tumour evolution differs; a RICH is completely regressed at a median age of 13.2 months. A PICH undergoes partial involution and stabilises at a median age of 
12.6 years. During long-term follow-up, pain is frequently reported by NICH and PICH patients in absence of any inflammatory manifestations, nor low platelet count. In a study of an NICH series, Lee et al reported pain in $43 \%$ of patients, dysesthesia was frequently reported rather than neuropathic pain, and they hypothesised that vasoconstriction may trigger local tissue ischaemia. ${ }^{24}$ In our patients, we observed hyperplastic nerve bundles in some lesions; these may contribute to the reported neuropathic symptoms as noticed in some painful vascular malformations. ${ }^{17}$ For most RICH patients, a wait-and-see approach is recommended; no effective medical treatment is known. If life-threatening complications develop, if aesthetic issues become of major concern or if a functional prejudice is in play, surgical excision (with or without preoperative embolisation to control bleeding) is indicated.

\section{Management of congenital haemangioma}

- Congenital haemangiomas are vascular tumours of infancy that are fully developed at birth.

- Three subtypes of congenital haemangiomas have been described based on clinical behaviour: rapidly involuting congenital haemangioma (RICH), non-involuting congenital haemangioma (NICH), or partially involuting congenital haemangioma (PICH) tumours.

- Similar clinical and histological findings in congenital haemangioma, suggesting that $\mathrm{RICH}, \mathrm{NICH}$ and $\mathrm{PICH}$ belong to the same spectrum.

- RICH and PICH cannot be distinguishing at birth, and only two-third of 'typical RICH' at birth will undergo complete involution (and finally, the other third will be diagnosed as PICH).

- The occurrence of ulceration is suggestive to a future incomplete involution, as it was more frequently reported in PICH.

- Most congenital haemangiomas did not require any treatment. Surgery may be indicated in case of haemorrhage.

- RICH and NICH may be associated with transient thrombopenia at birth, which must be distinguished from Kasabach-Merritt phenomenon, as it resolves spontaneously within 2 weeks.

- NICH may develop late neuropathic pain on their lesion, which can be caused by intralesional nerve dystrophy.

\section{CONCLUSION}

We describe the evolution of the three $\mathrm{CH}$ subtypes. We confirm that they exhibit overlapping features, suggesting that they lie on the same disease spectrum. Mulliken and Enjolras ${ }^{9}$ hypothesised that RICH preceded NICH; involution occurred in utero to yield NICH whereas regression commenced after birth to yield RICH. Thus, PICH constituted the missing link between these two $\mathrm{CH}$ subtypes. If a $\mathrm{CH}$ appears to be a $\mathrm{RICH}$ at birth, caution must be exercised when discussing prognosis with parents; involution does not cease in one-third of patients, who thus develop PICH. Ulceration seems to predict incomplete lesional involution, suggestive of PICH. Also, PICH and NICH patients frequently report neuropathic pain, possibly attributable to the abundant nerve bundles within the tumours.
Contributors VB collected data, carried out the initial analyses and drafted the initial manuscript. CG collected data. FB, AT and SP collected data and critically reviewed the manuscript for important intellectual content. NG collected data and performed imaging. ML collected data and performed surgery. M-LJ analyse all histological samples. CL-L conceptualised and designed the study, coordinated and supervised data collection, and revised the manuscript. All authors approved the final manuscript as submitted and agreed to be accountable for all aspects of the work.

Funding The authors have not declared a specific grant for this research from any funding agency in the public, commercial or not-for-profit sectors.

Competing interests None declared.

Patient consent for publication Parental/guardian consent obtained.

Ethics approval The study was approved by our local ethics committee.

Provenance and peer review Not commissioned; externally peer reviewed.

Data availability statement Data of our study are available on reasonable request.

Open access This is an open access article distributed in accordance with the Creative Commons Attribution Non Commercial (CC BY-NC 4.0) license, which permits others to distribute, remix, adapt, build upon this work non-commercially, and license their derivative works on different terms, provided the original work is properly cited, appropriate credit is given, any changes made indicated, and the use is non-commercial. See: http://creativecommons.org/licenses/by-nc/4.0/.

ORCID iD

Sorilla Prey http://orcid.org/0000-0003-0272-2640

\section{REFERENCES}

1 Boon LM, Enjolras O, Mulliken JB. Congenital hemangioma: evidence of accelerated involution. J Pediatr 1996;128:329-35.

2 Bruckner AL, Frieden IJ. Hemangiomas of infancy. J Am Acad Dermatol 2003:48:477-96.

3 Berenguer B, Mulliken JB, Enjolras O, et al. Rapidly involuting congenital hemangioma: clinical and histopathologic features. Pediatr Dev Pathol 2003;6:495-510.

4 Enjolras O, Mulliken JB, Boon LM, et al. Noninvoluting congenital hemangioma: a rare cutaneous vascular anomaly. Plast Reconstr Surg 2001;107:1647-54.

5 Nasseri E, Piram M, McCuaig CC, et al. Partially involuting congenital hemangiomas: a report of 8 cases and review of the literature. J Am Acad Dermatol 2014;70:75-9.

6 Léauté-Labrèze $\mathrm{C}$, Harper Jl, Hoeger $\mathrm{PH}$. Infantile haemangioma. Lancet 2017;390:85-94.

7 Lafitte A-S, Dolley P, Le Coutour X, et al. Rate of caesarean sections according to the Robson classification: Analysis in a French perinatal network - Interest and limitations of the French medico-administrative data (PMSI). J Gynecol Obstet Hum Reprod 2018;47:39-44.

8 Enjolras O, Picard A, Soupre V. [Congenital haemangiomas and other rare infantile vascular tumours]. Ann Chir Plast Esthet 2006;51:339-46.

9 Mulliken JB, Enjolras O. Congenital hemangiomas and infantile hemangioma: missing links. J Am Acad Dermatol 2004;50:875-82.

10 Putra J, Gupta A. Kaposiform haemangioendothelioma: a review with emphasis on histological differential diagnosis. Pathology 2017;49:356-62.

11 Gorincour G, Kokta V, Rypens F, et al. Imaging characteristics of two subtypes of congenital hemangiomas: rapidly involuting congenital hemangiomas and non-involuting congenital hemangiomas. Pediatr Radiol 2005;35:1178-85.

12 Agesta N, Boralevi F, Sarlangue J, et al. Life-Threatening haemorrhage as a complication of a congenital haemangioma. Acta Paediatr 2003;92:1216-8.

13 Krol A, MacArthur CJ. Congenital hemangiomas: rapidly involuting and noninvoluting congenital hemangiomas. Arch Facial Plast Surg 2005;7:307-11

14 Marler JJ, Fishman SJ, Upton J, et al. Prenatal diagnosis of vascular anomalies. J Pediatr Surg 2002;37:318-26.

15 Brix M, Soupre V, Enjolras O, et al. [Antenatal diagnosis of rapidly involuting congenital hemangiomas $(\mathrm{RICH})]$. Rev Stomatol Chir Maxillofac 2007;108:109-14.

16 El Zein S, Boccara O, Soupre V, et al. The histopathology of congenital haemangioma and its clinical correlations: a long-term follow-up study of 55 cases. Histopathology 2020;77:275-83. 
17 Meijer-Jorna LB, Breugem CC, de Boer OJ, et al. Presence of a distinct neural component in congenital vascular malformations relates to the histological type and location of the lesion. Hum Pathol 2009;40:1467-73.

18 Ayturk UM, Couto JA, Hann S, et al. Somatic activating mutations in GNAQ and GNA11 are associated with congenital hemangioma. Am J Hum Genet 2016;98:789-95.

19 Weitz NA, Lauren CT, Starc TJ, et al. Congenital cutaneous hemangioma causing cardiac failure: a case report and review of the literature. Pediatr Dermatol 2013;30:e180-90.

20 Baselga E, Cordisco MR, Garzon M, et al. Rapidly involuting congenital haemangioma associated with transient

thrombocytopenia and coagulopathy: a case series. $\mathrm{Br} J$ Dermatol 2008;158:1363-70.
21 Vildy S, Macher J, Abasq-Thomas C, et al. Life-Threatening hemorrhaging in neonatal ulcerated congenital hemangioma: two case reports. JAMA Dermatol 2015;151:422-5.

22 Al Malki A, Al Bluwi S, Malloizel-Delaunay J, et al. Massive hemorrhage: a rare complication of rapidly involuting congenital hemangioma. Pediatr Dermatol 2018;35:e159-60.

23 Acebo E, Gardeazábal J, González-Hermosa R, et al. Congenital hemangioma: a report of evolution from rapidly involuting to noninvoluting congenital hemangioma with aberrant Mongolian spots. Pediatr Dermatol 2009;26:225-6.

24 Lee PW, Frieden IJ, Streicher JL, et al. Characteristics of noninvoluting congenital hemangioma: a retrospective review. J Am Acad Dermatol 2014;70:899-903. 